\title{
Las constelaciones literarias como proyecto educativo para incentivar la lectura del género poético: "Las cuatro galaxias de Góngora"'
}

\author{
Literary Constellations as an Educational Project to Incentivize Reading \\ in the Poetry Genre: "Góngora's Four Galaxies"
}

\author{
ANDREA ARIÑO-BIZARRO \\ Universidad de Zaragoza \\ España \\ aribiz@unizar.es
}

(Recibido: O4-OI-2O2I; aceptado: $\mathrm{II}-\mathrm{O} 3-2 \mathrm{O} 2 \mathrm{I})$

Resumen. Hace ya tiempo que numerosos investigadores comparten la convicción de que la educación literaria de los adolescentes reclama otros caminos que los habitualmente transitados. Con la intención de renovar las iniciativas educativas, se diseñó una propuesta de intervención pedagógica basada en el concepto de las "constelaciones literarias" establecido por Jover en 2007, y fundamentada en las estrategias de innovación docente de la gamificación. En este contexto, se presenta un proyecto de innovación educativo centrado en el fomento del hábito lector titulado "Las cuatro galaxias de Góngora: un universo de estrellas por descubrir". En él se ofrece una propuesta de incentivación a la lectura del género poético que consiste en la creación de cuatro itinerarios lectores a partir de cuatro poemas del escritor barroco Luis de Góngora y Argote. Los resultados obtenidos han sido positivos, gracias a esta iniciativa, no solo el alumnado mejora su competencia literaria, sino que aumenta su interés por la poesía barroca al relacionarla intertextualmente con producciones artísticas diversas $y$, sobre todo, próximas a su contemporaneidad.

Palabras clave: literaria; innovación pedagógica; poesía; constelaciones literarias; gamificación.
Abstract. For some time now, many researchers have shared the conviction that the literary education of adolescents requires other pathways than those habitually travelled. With the intention of renewing educational initiatives, a pedagogical intervention proposal is presented based on the concept of "literary constellations" by Jover, 2007 , on the teaching innovation strategies of gamification. In this context, an educational innovation project focused on promoting the reading habit, entitled "Góngora's Four Galaxies: A Universe of Stars to be Discovered," is presented. The aim of that proposal is to encourage reading of the poetic genre that consists in the creation of four reading itineraries from four poems by the baroque writer Luis de Góngora y Argote. The results obtained have been positive, thanks to this initiative. Not only do students improve their literary competence, but they also increase their interest in baroque poetry by relating it intertextually with diverse artistic productions and, above all, close to their contemporaneity.

Keywords: literary competence; pedagogical innovation; poetry; literacy constellations; gamification.

\footnotetext{
${ }^{\text {I }}$ Para citar este artículo: Ariño-Bizarro, Andrea (2O2I). Las constelaciones literarias como proyecto educativo para incentivar la lectura del género poético: "Las cuatro galaxias de Góngora". Alabe 24. [www.revistaalabe.com]

DOI: IO.I5645/Alabe2O2I.24.8
} 


\section{Introducción}

Aunque nunca se ha leído tanto como en la actualidad ni nunca han existido tantos lectores (Federación de Gremios de Editores de España, 2OI9, Larrañaga y Jubero, 20I8); leer sigue sin estar de moda (Cerrillo y Senís, 2005; Moreno, Guzmán y García, 2OI7; Serna, Rodríguez y Etxaniz, 2OI7). Estudios recientes han evidenciado que la lectura es una actividad muy poco valorada por la sociedad, por los medios de comunicación y particularmente, por los jóvenes (Cassany, 2oi6; Trigo Ibañez, Santos Díaz y Sánchez Rodríguez, 2020). Pocos de los adolescentes leen textos que no sean instrumentales ya que la lectura por la lectura, por gusto, por enriquecimiento personal, ya no son objetivos básicos (Bustamante, Alzaga Ruiz y Observatorio de Cultura y Comunicación, 2OI7; Cordón-Garcia, 20I6; García-Roca, 20I9). En este sentido, el comportamiento lector hoy es más diverso (Tabernero Sala, Álvarez Ramos y Heredia Ponce, 2020). El nuevo lector prefiere la lectura fragmentada, discontinua y segmentada (Peña, 2OIO: p.3), por lo que la práctica lectora incluye nuevos formatos, como el digital (McKenna, Conradi, Lawrence, Gee y Meyer, 20I2).

A la luz de lo expuesto, el fomento del hábito lector tiene que tomar nuevos retos en estos tiempos que inician el tercer milenio (Ballester e Ibarra, 20o9; Ballester-Roca e Ibarra-Rius, 20ı6; Millán, 2000). Estos desafíos van a exigir utilizar estrategias que consigan atrapar al lector adolescente de hoy (Álvarez, Heredia y Romero, 20I9; Amar, 20I7; Fraguela, Pose y Varela, 20I6). Para ello, las propuestas deben ser capaces de responder a los criterios de libertad y autonomía crítica que caracterizan al individuo de la sociedad del presente para, de este modo, conseguir que nazcan nuevos lectores competentes (Ambrós y Breu, 20I4; Martos Núñez, 2OI3).

Aplicando esta pretensión al ámbito de la educación literaria, la escuela debe hacer frente a la triple misión de enseñar a leer, consolidar hábitos lectores y compartir un imaginario colectivo (Jover, 2009). Es precisamente esta triple misión mediante la cual se ha producido la sustitución de la expresión «enseñanza de la literatura», entendida como transmisión de un patrimonio nacional, por la de «educación literaria», concebida como el desarrollo de aquellos conocimientos, estrategias y actitudes necesarios para crear lectores competentes y autónomos de literatura a lo largo de toda la vida (LOMCE, p.97860).

En esta línea, hace ya tiempo que numerosos investigadores comparten la convicción de que la educación literaria de los adolescentes reclama otros caminos de los habitualmente transitados (Martínez y González, 2OIO; Rojas-Castro, 2OI7; Romero, Trigo y Moreno, 20I8)², y que, más allá de las iniciativas individuales, andamos necesitados de construir, colectivamente, una alternativa a la tradición escolar consistente en la transmisión enciclopédica de la historia literaria nacional (Jover, 2009).

\footnotetext{
${ }^{2}$ Aunque la apuesta del siglo XXI por la educación literaria lleva tiempo siendo demandada, Zayas (2OII) afirma que todavía se continúa enseñando literatura como la mera transmisión de conocimientos sobre un conjunto de autores y obras considerados como un patrimonio nacional.
} 
Con la intención de renovar las iniciativas educativas, en esta propuesta de innovación educativa se ha escogido el género poético porque, aunque se ha apuntado repetidamente que la poesía es difícil de introducir en el aula (Zaldívar, 20I7; Zaldívar Sansuán, 202O), se piensa que las mismas características que le confieren esa dificultad son las que le proporcionan enormes ventajas educativas (López Herrerías, 2003; Gómez Martín, 2002; Zaldívar Sansuán, 20I4; Zayas, 2OII). Por este motivo, es necesario insistir en que la poesía regrese a las escuelas, puesto que será mucho más difícil que los maestros y los alumnos regresen a la poesía (Argüelles, 20I6).

En este sentido, el valor principal de este proyecto de incentivación a la lectura consiste en promover el interés por el género poético en el alumnado a partir de la construcción de cuatro itinerarios lectores que partan de sus intereses y contemplen, al mismo tiempo, los contenidos del currículo de la ESO (Góngora y la poesía barroca). Para llevar a cabo dicho propósito, los objetivos específicos que se persiguen son:

- Objetivo i. Aumentar la competencia literaria del alumnado con respecto al género poético del autor barroco, Góngora, a través de su relación con otros poemas, otros géneros literarios e incluso, con otras manifestaciones artísticas, que consigan que el alumno establezca lazos de intertextualidad.

- Objetivo 2. Ofrecer lecturas mediatizadas y adecuadas al contexto del aula a través de metodologías pedagógicas de innovación como la gamificación y las constelaciones literarias.

\section{Marco teórico}

\section{I. La poesía en los centros de secundaria}

Eclipsada por la narrativa y el teatro, la poesía queda en la retaguardia de los programas escolares de la escuela secundaria (Bibbó, 20I6; Millán, 2008; Molina Villaseñor, 20I6). Aunque en el currículo se estipula que deben ser trabajados todos los géneros literarios sin distinción, Argüelles reconoce que "la escuela, y en general, el sistema escolar, por lo menos en el ámbito iberoamericano, han hecho muy poco para que los niños y los jóvenes aprendan a leer poesía y con ello, se aficionen a la lectura de este género" (20I6: I6).

Multitud de autores consideran que esta marginación del género poético se debe a que, dentro del espacio educativo de la lectura, la poesía es el género que tradicionalmente ha sido considerado más difícil (Bordons, 2002; Fernández y Llorens, 2005). Además, Ballester e Ibarra (2OI6) reconocen que quizás la concepción que más daño ha generado respecto a su inclusión en las aulas estribe en su consideración exclusiva como objeto estético en detrimento de un posible valor educativo. Junto a la dificultad de comprensión del género poético y su aparente nulidad formativa, Ambrós y Ramos (2007) agregan otra de las posibles razones que explican su poca incorporación en el sistema escolar: la lejanía entre la poesía culta y la sociedad, que la convierte en una lectura aparentemente poco motivadora. Por todo esto, las nuevas generaciones leen muy poca poesía y son mu- 
chos los lectores que confiesan abiertamente que no saben leerla o que no la entienden (Zaldívar, 2OI4, 2OI7).

No obstante, la poesía, gracias a sus rasgos inherentes, supone una valiosa opción educativa en la que se fusionan el valor formativo para poder aprehender, interpretar y entender la realidad, con la adquisición de conocimientos, el desarrollo de capacidades, habilidades y competencias diversas (Gómez Martín, 2002; López Herrerías, 2003; Zayas, 2OII).

En este sentido, el género poético tiene que presidir un lugar destacado en la formación de los jóvenes ya que la apreciación de la belleza, la valoración de los sentimientos y la necesidad de la proyección creativa son cada vez más necesarios en nuestra sociedad (Gómez, 2002; Zaldívar Sansuán, 2020). Esta situación ha hecho que multitud de estudiosos se planteen la necesidad de dedicar más tiempo a diseñar cómo podemos enseñar este género para que el alumnado consiga verse reflejado en el espejo de la poesía (Ambrós y Ramos, 2007; Ballester-Roca e Ibarra-Ruiz, 20I6; Bombini y Lomas, 20I6; García Carcedo, 20I8). Por esta razón, proponen que el docente, actuando como mediador, parta de la consideración de la realidad y experiencia vitales de sus alumnos para más tarde implicarse en la valoración de los posibles objetos poéticos que puede llevar al aula (Arenas Delgado, Otero Doval y Tatoj, 2O2O; Caride, Caballo y Gradaílle, 20I8; Munita y Manresa, 2OI2). Con este interés, se impulsó la idea de las constelaciones literarias de Jover en 2007 .

\subsection{El concepto de "Constelación Literaria"}

La propuesta metodológica de Jover (2007) llamada constelaciones literarias plantea la necesidad de modificar el papel de la literatura dentro de los planes de estudios actuales desechando la prescripción de obras fijas y apostando por proyectos de carácter hipertextual. En este sentido, las constelaciones literarias hacen referencia a la posibilidad de trazar líneas imaginarias entre unas obras y otras pese a su posible lejanía recíproca en el espacio y en el tiempo. Así pues, ilustran el modo en que, de manera análoga a como hemos hecho con las estrellas del firmamento, podemos también establecer vínculos entre unas obras y otras desde nuestra perspectiva de observadores. Las constelaciones literarias, por tanto, son construcciones interpretativas cuyos vínculos imaginarios los determina el espectador.

En el contexto educativo, lo relevante es hacer explícitos estos vínculos imaginarios que llevan a aproximar unas a otras (Jover, 20o8). Por ello, es esencial que hagamos manifiestos los criterios que nos llevan a conectar unos títulos con otros. Así pues, las constelaciones literarias se convierten en una estrategia de fomento del hábito lector que pretende que el individuo viaje de una lectura a otra dentro de tres dimensiones: la temporal, la social, y la contextual (Clandinin y Conelly, 2000). Ese viaje implica que cada estudiante elabore sus propias constelaciones literarias a través de distintas obras artísticas a partir de la cuales crear una red de caminos subjetivos. Con ello, el alumno se convierte en protagonista del proceso de enseñanza-aprendizaje y actúa como mediador 
de su propio itinerario lector (Guiñez \& Martínez, 20I5; Mendoza Fillola, 2008).

En esta línea, Jover reivindica una renovación del corpus de textos y considera vital la composición de un nuevo canon literario para la escuela: "un canon cosmopolita, escolar (esto es, pensado para el lector real de las aulas de secundaria) y mixto (que combine, en proporciones variables, literatura clásica y literatura juvenil actual)" (2O09: II). Por este motivo, propone ceder el protagonismo al alumno en la elección de las lecturas ya que, como reconoce la ley educativa vigente, el alumnado es el centro y la razón de ser de la educación (LOMCE: $97^{8} 5^{8}$ ).

Por consiguiente, a través de las constelaciones literarias, se ofrece un canon mixto que combina literatura juvenil con literatura clásica, lo que permite conformar la experiencia lectora del alumno (Garvis, 20I5; Rovira-Collado, 20I9). Con ello, Jover señala que el docente logra desarrollar una lectura «en contrapunto» de textos del pasado y del presente, de textos literarios y de otro tipo de discursos indisolublemente ligados a la actualidad de nuestros jóvenes lectores: la publicidad, la televisión, el cine, etc.

En la práctica se trata de construir un itinerario lector que combine textos de hoy y de ayer y de cualquier tradición teniendo siempre presente que el centro de interés es el alumno. Por tanto, se instiga a crear un nuevo canon literario escolar y mixto pensado para el alumno de Secundaria.

Para ello, los profesores, en su actividad de mediación, tienen que realizar con anterioridad una exhaustiva y pertinente labor de rastreo de autores y obras que aseguren que estas lecturas contribuyen en la formación de lectores competentes (Rojas-Castro 2OI7; Romero-Oliva, Trigo-Ibáñez y Moreno-Verdulla, 20I8). Estriba en el profesorado, por tanto, la responsabilidad de proporcionar un repertorio amplio en todos los sentidos (Ballester-Roca e Ibarra-Rius, 20I6).

En este repertorio es interesante que se incluyan tanto textos de la literatura clásica y universal, como aquellos más próximos al alumno en el tiempo y en el contexto (Ayuso Collantes, 202O). Por ello, en la selección de lecturas no se trata de renunciar a un acervo de cultura común, a un preciso imaginario compartido, sino de ampliarlo para que la lectura en el aula no sea rehén de los cánones únicos e inamovibles.

\subsection{La poesía del barroco en el aula: el caso de Luis de Góngora y Argote}

Digámoslo con rotundidad, de una vez por todas: los clásicos son irrenunciables (Jover, 2008: I62). Con esta aserción, Jover reafirma la necesidad de conformar constelaciones literarias que atiendan los intereses de los alumnos pero que, al mismo tiempo, les dote de una experiencia literaria total. Por esto, el corpus de textos que propone combina la literatura juvenil con la literatura de clásicos (véase apartado 2.2.).

Desde este punto de partida, y tomando como base fundamental lo expuesto hasta el momento, centramos nuestro interés en la literatura barroca ${ }^{3}$, y en concreto, en uno de sus poetas más representativos: Luis de Góngora y Argote.

\footnotetext{
3 Aunque esta propuesta de innovación didáctica es extrapolable a toda obra, figura y movimiento, no obstante, hay una época a la que podemos reconocerle una absoluta y descarada actualidad: el periodo barroco (Ramos, 20I5: 82).
} 
La poesía barroca y, sobre todo, la poética de Góngora suele ser la parte de la historia de la literatura que el alumno no comprende ya sea por el lenguaje adornado que usa en sus poesías o por el empleo del castellano antiguo de sus textos (Orta, 2OI2). La obra literaria de este autor del barroco presenta una amplia carga poética de gran densidad literaria lo que conlleva que el alumnado, reticente con el género poético en general, relegue este autor de su itinerario lector por considerarlo incomprensible y alejado de sus preocupaciones diarias. En principio parece razonable considerarlo el menos indicado al nivel cultural y a la pereza lectora de nuestros alumnos, a quienes luchar con sus dificultades podría resultar contraproducente. Sin embargo, el ocuparse de literatura difícil en el sistema educativo no es problema de alumnos sino de profesores (Carreira, I993).

Por este motivo, no podemos eliminar de nuestras enseñanzas obras y autores excelsos por el simple hecho de considerarlos difíciles. Al contrario, Carreira (I993) advierte que no solo no deberíamos pasar por alto poetas como Góngora, sino que habríamos de insistir en estudiarlos, pues son precisamente los que más requieren la labor docente. En este sentido, los docentes tienen que estar comprometidos y utilizar estrategias educativas que permitan acercar la poética de Góngora al alumnado para conseguir que la dificultad de su lectura se disipe.

Con este fin, las constelaciones literarias propuestas por Jover (2007, 2008, 2009) permiten que el alumnado se sienta partícipe y no un simple espectador pasivo. En esta línea, es conveniente plantear la didáctica de la Literatura, y en este caso de la poesía, desde una óptica comparatista que permita trascender la estricta parcelación del conocimiento en torno a un único eje histórico-lingüístico (Ayuso Collantes, 202O; Mendoza Fillola, 20I2). De este modo, los alumnos perciben que no entender todas y cada una de las imágenes que nos propone el poeta no significa que no comprendamos su poesía (Gómez, 2002: I66). La comprensión total del poema no es lo fundamental, es preferible que: mostremos que la poesía de Góngora trata temas presentes en la contemporaneidad (no necesariamente debemos hablar de textos literarios, sino de producciones artísticas) y advirtamos a los alumnos de que su obra poética se alza como un diálogo poblado de referencias, citas, motivos puntuales compartidos que los conectan con la actualidad, bien conscientemente bien inconscientemente (Wyatt-Smith y Elkins, 20o8; Kress, 2OIO; Unsworth 20I4). Así y solo así conseguiremos el propósito que persigue la educación literaria: crear lectores competentes (Querol, 20II: 72). Y este objetivo es el que se ha perseguido en la propuesta didáctica "Las cuatro galaxias de Góngora: un universo de estrellas por descubrir". 


\section{Las cuatro galaxias de Góngora: una propuesta de incentivación a la lectura del género poético}

\section{I. Contexto y metodología de evaluación del proyecto de innovación}

El presente proyecto de innovación tuvo lugar en el Colegio San Valero (Escuelas Pías) de Alcañiz del 6 de marzo al 28 de abril de 20r8. El grupo-clase en el que se desarrolló fue el curso de $3 .{ }^{\circ}$ de ESO del Colegio San Valero (Escuelas Pías) de Alcañiz. La edad media del alumnado era de I 4,5 años; y el número de chicos y chicas estaba equilibrado: I3 alumnos y i2 alumnas.

Para conocer el grado de consecución del Objetivo I, se establecieron dos técnicas de evaluación diversas: (i) la observación directa del grupo clase por parte del docente a través de un diario de clase y (ii) la cumplimentación de una rúbrica de observación durante el desarrollo y consecución del proyecto (tanto para el profesor como para el alumno). Por su parte, para conocer el grado de consecución del Objetivo 2, fue necesario la implementación de un cuestionario de evaluación de la propuesta a partir de la técnica del One minute paper. ${ }^{4}$

\subsection{Propuesta Didáctica}

\subsection{Descripción General}

El proyecto de innovación "Las cuatro galaxias de Góngora: un universo de estrellas por descubrir" consistió en la creación de cuatro constelaciones literarias a partir de cuatro de los poemas más representativos del escritor barroco Luis de Góngora y Argote.

Para su diseño, se implementaron dos metodologías pedagógicas diferentes: por una parte, la metodología desarrollada por Jover en su obra Un mundo por leer (2007) y la cristalización de su concepto de "constelaciones de lectura" (véase apartado 2.2.); y, por otra, herramientas educativas extraídas de una técnica de intervención pedagógica innovadora, la gamificación (Marín, 20I5; Rovira-Collado, Serna Rodrigo y Bernabé Gallardo, 20I6). Para ello, se usaron estrategias lúdicas y características propias de los juegos en un contexto educativo, con el propósito de crear una experiencia que favorezca la motivación, la implicación y la diversión de los estudiantes (Gallego, Molina y Llorens, 2OI4: 2). Con este fin, Cano afirma que: "gamificando algo percibido como "tedioso" o "aburrido" -como la lectura de poemas- logramos que el participante lo tome como algo en lo que tiene ganas de implicarse" (Serna, 20I6: I5).

De este modo, la propuesta que aquí se presenta parte del concepto de constelación literaria y su desarrollo se establece como una actividad lúdica. Así pues, en primer lugar, los alumnos tienen que identificarse como "astrónomos literarios". En su rol de "astrónomos literarios", su tarea consiste en descubrir cuatro nuevas "galaxias litera-

\footnotetext{
${ }^{4} \mathrm{El}$ one minute paper hace referencia a "un conjunto de técnicas docentes, también conocidas como papel al minuto, las cuales, con carácter general, implican la resolución de un conjunto limitado de cuestiones una vez finalizada una sesión de clase" (Sáez y Rodríguez, 2003: 20). Estas preguntas siempre deben tener una redacción clara, de respuesta abierta y breve, así como referida a la percepción del alumno sobre unos contenidos de la clase que ha finalizado u otras actividades realizadas (Morales, 2OII).
} 
rias" que les orientarán en sus lecturas posteriores. A través de ellas, tienen, por tanto, que crear itinerarios lectores conformados por diferentes estrellas (obras literarias y artísticas). Estos itinerarios, como científicamente se explican las galaxias, deben partir de un lugar común. Este punto de partida, que astronómicamente se denomina núcleo galaico, es la estrella principal de la "galaxia literaria", en este caso, un soneto de Luis de Góngora. Partiendo de la definición de este término astronómico, es necesario establecer también un eje gravitatorio común gracias al cual todas las estrellas estén interconectadas. En esta propuesta, el eje que conecta el núcleo galaico (el soneto de Góngora) con el resto de las estrellas (obras literarias y artísticas) son los tópicos literarios ${ }^{5}$. En esta línea, los elementos que constituyeron dichas constelaciones, para los alumnos "galaxias", fueron en esencia muy diversos, a saber: desde sonetos de Luis de Góngora, pasando por obras literarias poéticas, ya fueran clásicas o contemporáneas, hasta canciones, obras literarias narrativas, obras pictóricas e, incluso, películas.

Para llevar a cabo dicho proyecto, se estableció una secuencia didáctica estructurada en tres fases organizadas temporalmente a partir de un cronograma (véase Tabla I).

\begin{tabular}{|c|l|}
\hline \multicolumn{1}{|c|}{ Secuencia Didáctica } & \multicolumn{1}{c|}{ Temporalización } \\
\hline $\begin{array}{c}\text { Fase Preparación } \\
\text { A. Fase de Preparación del docente } \\
\text { B. Fase de Presentación propuesta }\end{array}$ & $\begin{array}{l}\text { Trabajo Individual (aprox. 20 horas) } \\
2 \text { sesiones (aprox. 110 minutos) }\end{array}$ \\
\hline $\begin{array}{c}\text { Fase Realización } \\
\text { Fase Evaluación } \\
\text { A. Evaluación Objetivo 1. } \\
\text { B. Evaluación Objetivo 2 }\end{array}$ & 2 sesiones (aprox. 110 minutos) \\
\hline
\end{tabular}

Tabla 1. Cronograma de estructuración de la secuencia didáctica

\subsubsection{Fase de preparación}

\section{A. Fase de preparación por parte del docente}

La elección de textos y manifestaciones artísticas es clave para atender a la libertad de elección, principio esencial de la metodología pedagógica de las constelaciones literarias. Por esta razón, fue conveniente ofrecer un corpus de lectura flexible y abierto que atendiera a las particularidades de los lectores y a su contexto.

El primer paso fue, por tanto, leer textos de distintos géneros y épocas para poder estructurar una propuesta que abarcase los géneros y contenidos adecuados para los

\footnotetext{
5 Los tópicos literarios son "motivos semánticos concretos que se manifiestan literariamente mediante una forma perceptible y definible y que muestran recurrencia en la historia de la literatura occidental” (Laguna, I999: 2OI).
} 
alumnos-participantes. Consideramos oportuno precisar que serán muchos los títulos o territorios que el lector eche en falta en nuestra propuesta. Las líneas que siguen no pretenden ejemplificar un único "programa de educación literaria” sino abrir los márgenes en la intervención educativa con una propuesta renovadora.

En esta línea, fue imprescindible consultar el currículo de Educación Secundaria Obligatoria (BOE Real Decreto IIO5/2OI4) y conocer cuáles son las obras y periodos literarios establecidos como objetivos específicos de la materia de Lengua Castellana y Literatura. Su consulta fue clave, por ende, para instaurar la estrella clave de cada una de las constelaciones: los sonetos de Luis de Góngora.

Una vez elegida la estrella principal de la constelación, era necesario partir de un concepto común que fuera el eje estructural de la galaxia literaria. En las constelaciones realizadas por Jover (2008) el eje que estructura las galaxias literarias suele ser el temático. Sin embargo, al ser el género poético el punto de partida en esta propuesta se consideró oportuno diseñar cada uno de los itinerarios lectores a partir de un concepto temático muy estudiado en el género poético: los tópicos literarios (Morales, 2005). En este sentido, se seleccionaron cuatro de los tópicos más recurrentes en la obra de Góngora (Micó, 20I5) y que, además, aparecen explicados en los libros de texto de diferentes editoriales educativas destinadas a la Educación Secundaria. De esta manera, los cuatro tópicos literarios establecidos fueron: (i) Descriptio Puellae, (ii) Locus Amoenus/Terribilis, (iii) Carpe Diem y (iv) Memento Mori.

A partir de ellos, se diseñaron las constelaciones, partiendo de cuatro sonetos de Luis de Góngora, tomados de la antología titulada: Luis de Góngora para niños (Góngora, I99I $)^{6}$. Los poemas escogidos fueron los siguientes: soneto titulado "Mientras por competir por tu cabello" (Constelación Carpe Diem), soneto titulado "Ya besando unas manos cristalinas" (Constelación Descriptio Puellae), soneto titulado "Verdes juncos del Duero a mi pastora" (Constelación Locus Amoenus/Terribilis) y soneto titulado "De la brevedad engañosa de la vida" (Constelación Memento Mori).

Estas constelaciones conformadas por el docente se configuraron previa puesta en práctica del proyecto y se encuentran en formato tabla en el Anexo I. No obstante, estas constelaciones no se configuraron exclusivamente por el docente, puesto que el alumnado aportó ideas para cada una de las constelaciones. Por esta razón, los estudiantes fueron quienes construyeron cada una de las galaxias literarias a partir de su competencia literaria. De este modo, el docente les facilitó las estrellas de la constelación (siendo muchas de estas estrellas facilitadas por los estudiantes) y estimuló su capacidad investigadora para que fueran ellos quienes conformaran las galaxias a partir de sonetos de Luis de Góngora.

\footnotetext{
${ }^{6}$ Se recomienda consultar las antologías editadas por Carreira tituladas Antología poética, Góngora (i986) y Antología poética (Clásica) (2005) para desarrollar esta misma propuesta en niveles educativos superiores.
} 


\section{B. Fase de presentación de la propuesta al grupo clase}

Por la importancia que tiene esta fase, se destinaron dos sesiones de 50 minutos cada una a la presentación de la propuesta. En la primera sesión, se proporcionó a los alumnos las siguientes instrucciones: "como las constelaciones creadas por los seres humanos tomando un criterio subjetivo pero explícito, pretendemos durante la realización de este proyecto establecer cuatro constelaciones literarias, las cuales presentan características muy próximas a las espaciales".

Para facilitar la tarea y promover el trabajo en equipo de toda la clase, se establecieron tres grupos cooperativos 7 , dos grupos conformados por 6 estudiantes y uno por 7 estudiantes. Con el fin de utilizar las estrategias de gamificación, a los alumnos se les identificó en lo sucesivo como "investigadores de la NASA literaria", y cada grupo se correspondía con un equipo de trabajo de esta agrupación de científicos: (i) grupo Interestelar, (ii) grupo Intraestelar y (iii) grupo Estelar.

Tras la conformación de los grupos cooperativos, se expusieron los criterios de calificación y se le entregó a cada alumno la rúbrica destinada a evaluar su proyecto final. En lo sucesivo se explicó detalladamente el cometido de cada uno de los equipos conformados. Así pues, se resumió el propósito final del proyecto: "cada grupo cooperativo será el encargado de descubrir y estudiar una de las cuatro galaxias de Góngora”.

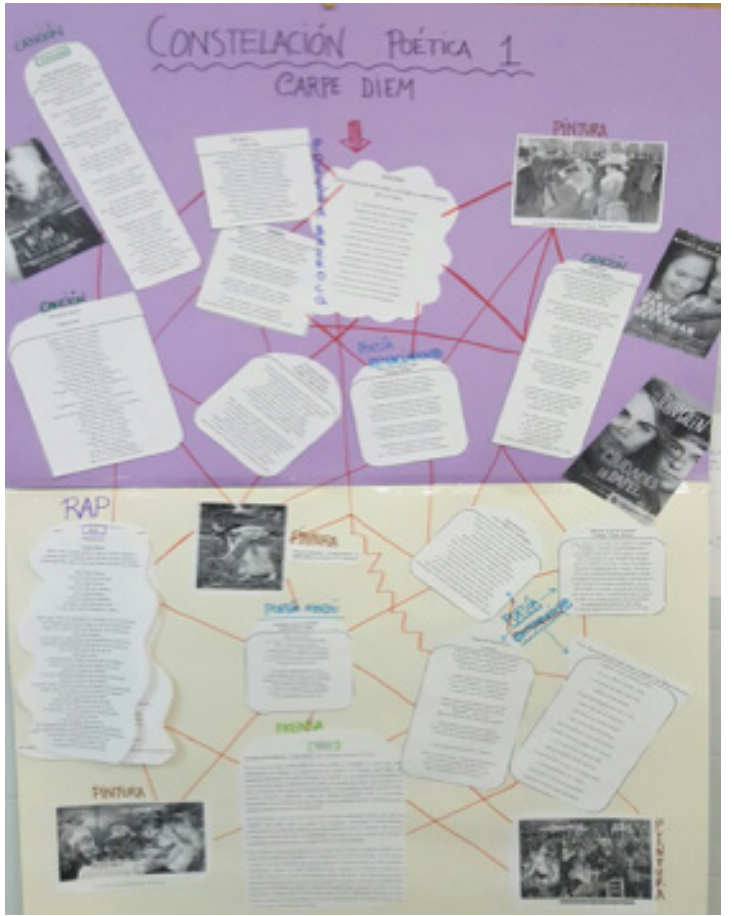

Figura 1. Fotografía de la Galaxia Hacuna Matata

En la segunda sesión, se les presentó la primera de las galaxias de Góngora, a la cual llamaron Hakuna Matata. Esta fue la única de las tres restantes que no tuvo que ser "descubierta" por los estudiantes. Con ella, por consiguiente, se mostró y exhibió el primer itinerario lector para que los alumnos pudieran partir de un modelo que les permitiera orientar su investigación posterior. En la Galaxia Hakuna Matata, el eje que vertebraba la relación de obras artísticas era el tópico del Carpe Diem. A partir de ella, se presentaron las estrellas que la conformaban con el propósito de que los estudiantes comprendieran en qué consistía descubrir una galaxia y qué resultado final tenían que obtener al terminar el proyecto (véase Figura I).

\footnotetext{
${ }^{7}$ La propuesta de trabajo cooperativo se entiende como "una asociación entre personas que van en busca de ayuda mutua en tanto que procura realizar actividades conjuntas, de manera tal que puedan aprender unos de otros" (Caldeiro y Vizcarra, 2009: I). .

${ }^{8}$ Los nombres de cada uno de los grupos de trabajo cooperativo fueron escogidos por los estudiantes que conformaban cada uno de ellos.
} 
Una vez se trabajó con el modelo de constelación, se establecieron los tres ejes a partir de los cuales los alumnos iban a tener que formar las tres constelaciones literarias restantes: el tópico de la Descriptio Puellae (para el Grupo Interestelar), el tópico del Memento Mori (para el Grupo Intraestelar) y el tópico del Locus Amoenus/Terribilis (para el Grupo Estelar). Antes de empezar el descubrimiento de cada una de las galaxias, y para que su búsqueda no estuviera condicionada, no se les entregó todavía los poemas de Góngora ni ninguna manifestación artística preparada por el docente. Para que los itinerarios fueran abiertos y libres (objetivo fundamental en las constelaciones literarias de Jover (2008)), se pidió a los alumnos que buscaran estrellas (obras artísticas y literarias) que pudieran estar relacionadas con el tópico galaico que les había tocado investigar.

\section{3·3.2. Fase de realización.}

A la fase de realización se le dedicaron dos sesiones en el aula. Como "astrónomos literarios", el estudiantado tuvo que identificar qué estrellas (obras artísticas) pertenecían a cada una de las constelaciones (galaxias) a partir de un hilo literario común (los tópicos literarios).

Los textos, de manera similar a cómo se encuentran las estrellas en el universo, fueron presentados ante ellos de manera dispersa y desordenada. Para saber cuál de estos textos o manifestaciones artísticas pertenecían a su constelación, los estudiantes tenían que entender qué significaba el tópico que les había sido asignado y, sobre todo, hacer uso de su comprensión lectora para entender las manifestaciones literarias y artísticas que se les presentaba.

Con este propósito, a cada grupo se le entregó por categorías distintas las diferentes estrellas integrantes de cada una de las constelaciones que el docente había esbozado con anterioridad, junto con las estrellas que los estudiantes habían buscado de manera voluntaria. De esta manera, cada equipo tuvo que decidir qué estrellas, esto es, qué obras literarias o artísticas, pertenecían a su galaxia siguiendo el criterio del tópico literario que vertebraba su constelación. Por consiguiente, si consideraban que dicha estrella no pertenecía a su constelación; debían recapacitar a cuál de las otras dos pertenecía y entregárselas a sus compañeros; puesto que todos ellos formaban parte del mismo equipo de trabajo: la NASA literaria.

A este respecto, no se repartieron todas las estrellas al mismo tiempo, sino que la actividad se estructuró en diferentes niveles o fases. De este modo, se comenzó con la entrega de las estrellas que estaban representadas por los poemas de Góngora por ser el astro principal de cada una de las galaxias. Así pues, cada grupo inició la actividad con la lectura de los tres poemas escogidos por el docente como integrantes de cada una de las galaxias. Los alumnos de cada uno de los grupos tuvieron que debatir cuál era la estrella de su constelación y una vez lo establecieron, redactaron un breve texto justificando el porqué.

Las siguientes estrellas que se distribuyeron en la segunda etapa fueron poemas próximos a los creados por el autor barroco Góngora, tanto de Lope de Vega, Quevedo 
o Garcilaso, entre otros (véase columna 4 de la tabla recogida en el Anexo I). En esta ocasión, se ofrecieron de manera aleatoria el cómputo total de estrellas de esta categoría y ellos tuvieron que decidir qué poemas estaban relacionados con su astro principal por el tópico vertebrador de la misma. Tras leer cada uno de esos poemas, el debate se inició de nuevo en cada uno de los grupos. Si consideraban que alguna de esas estrellas no pertenecía a su constelación, tenían la responsabilidad de facilitársela al grupo correspondiente para que todos pudieran completar su galaxia.

A continuación, se les facilitó poemas de autores contemporáneos (columna 5 de la tabla del Anexo I). De nuevo, la dinámica fue idéntica a la anterior. Sucesivamente, se realizó esto mismo con las canciones escogidas (columna 6 de la tabla del Anexo I). Así mismo, se presentaron las obras pictóricas, las películas y las novelas, tanto de Literatura Juvenil e Infantil como canónicas (columnas 7, 8 y 9, respectivamente, de la tabla del Anexo I). En estos últimos casos, como era complejo poder establecer su lectura completa, se les facilitó el título de la novela y ellos tuvieron que investigar en los miniportátiles del aula de qué versaba cada una y por qué se podía incorporar dentro de una de las constelaciones, y no en las otras.

Una vez que cada uno de los grupos cooperativos seleccionó las estrellas de su constelación, los diferentes equipos conformaron físicamente su galaxia y le dieron nombre (véase Figura 2) ${ }^{9}$.
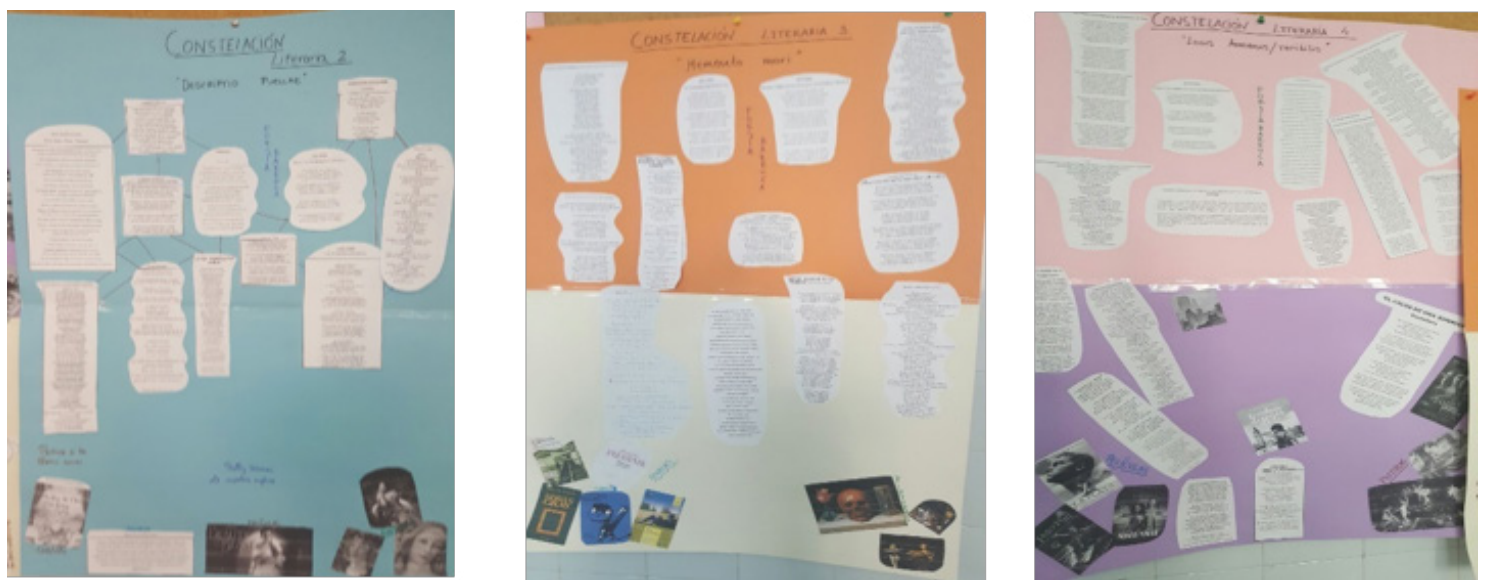

Figura 2. Fotografías de la Galaxia Galatea, Galaxia Hades y Galaxia Ebro, respectivamente.

Cada una de las constelaciones literarias fueron colgadas junto a una breve explicación del itinerario lector en el pasillo, fuera del aula, a la vista de todos los demás cursos.

\footnotetext{
${ }^{9}$ Los nombres que fueron otorgados por los alumnos a las tres galaxias "descubiertas" son los siguientes: Galaxia Galatea (Constelación vertebrada por el tópico de la Descriptio Puellae), Galaxia Hades (Constelación vertebrada por el tópico del Memento Mori) y Galaxia Ebro (Constelación vertebrada por el tópico del Locus Amoenus/Terribilis).
} 


\section{$3 \cdot 3 \cdot 3 \cdot$ Fase de evaluación}

En esta fase, se estudió el grado de consecución de los objetivos planteados. Para la evaluación del objetivo I, se utilizó un diario de clase completado por el docente durante el desarrollo del proyecto; y tras su finalización, la cumplimentación de una rúbrica de evaluación del proyecto final. El objetivo 2, por su parte, fue evaluado, por parte del alumnado, a través de la técnica del One minute paper.

\section{A. Evaluación del Objetivo I}

Una vez concluida la fase de realización, se valoró el producto final de la propuesta: la conformación de cada una de las galaxias. Esto se calificó a través de dos instrumentos de evaluación. Por una parte, a partir de un diario de clase redactado y cumplimentado por el docente. Y, por otra, mediante una rúbrica, también entregada a los alumnos en la fase de preparación, en la que se atendió a la comprensión lectora de poemas (si habían sabido localizar las estrellas de cada una de las constelaciones), a la presentación de las galaxias (originalidad en la parte creativa) y a los escritos explicativos de cada una de ellas para conocer si habían conseguido valorar positivamente la literatura y comprender la actualidad y vigencia de los tópicos literarios.

En suma, la calificación del proyecto de innovación fue estructurada de la siguiente forma: los apuntes de participación del diario de trabajo en el aula supusieron el 30 \% de la calificación final, la rúbrica completada por el docente suponía un 40 \% y, finalmente, esa misma rúbrica cumplimentada por el propio alumno autoevaluando su trabajo suponía el otro $30 \%$. ${ }^{\text {Io }}$

Los resultados de la evaluación final de cada uno de los proyectos y de cada uno de los grupos se recogen en la Tabla 2:

\begin{tabular}{|c|c|c|c|c|}
\hline Grupo & $\begin{array}{c}\text { Anotaciones del } \\
\text { Diario del Docente }\end{array}$ & $\begin{array}{c}\text { Rúbrica del } \\
\text { Docente }\end{array}$ & $\begin{array}{c}\text { Rúbrica del } \\
\text { Alumnado }\end{array}$ & $\begin{array}{c}\text { Puntuación } \\
\text { Total }\end{array}$ \\
\hline Interestelar & $30 \%$ & $35 \%$ & $30 \%$ & $95 \%$ \\
\hline Intraestelar & $30 \%$ & $30 \%$ & $28 \%$ & $88 \%$ \\
\hline Estelar & $30 \%$ & $40 \%$ & $30 \%$ & $100 \%$ \\
\hline
\end{tabular}

Tabla 2. Evaluación Final de cada una de las Constelaciones Literarias

Tras la evaluación tan positiva de la propuesta se comprobó que la puesta en práctica de nuevos enfoques didácticos como la gamificación y las constelaciones literarias permiten acercar el género poético al día a día del alumno para conseguir que comprenda y valore la lectura de poemas.

\footnotetext{
IO Consideramos que la autoevaluación, en una propuesta de tal envergadura, "es la estrategia para educar en la responsabilidad y para aprender a valorar, criticar y a reflexionar sobre el proceso de enseñanza y aprendizaje individual realizado por el discente" (Calatayud, 2002: 357).
} 


\section{B. Evaluación del Objetivo 2}

Todas estas conclusiones, además de hacerse evidentes en la calificación final del proyecto (todos los grupos aprobaron y obtuvieron más del $85 \%$ de la calificación), se mostraron también en el instrumento que evaluó la consecución de la propuesta general: el one minute paper (véase Anexo 2).

La primera pregunta del cuestionario, destinada a averiguar qué había sido lo que más había gustado de la propuesta, mostró la motivación e implicación que había supuesto para ellos realizar esta actividad. De este modo, algunas de las respuestas más repetidas fueron las siguientes: "lo que más me ha gustado es que hemos aprendido más y mejor", "lo que más me ha divertido es hacer las constelaciones en grupo", "gracias a este juego he entendido otros tipos de literaturas", "me ha encantado ver que las canciones están relacionadas con la literatura clásica", "la originalidad de la actividad porque parecía que estuviéramos jugando", entre otros.

En la segunda cuestión, centrada en los aspectos que les habían quedado menos claros o les había resultados más difíciles en su desarrollo, el alumnado afirmó que mayoritariamente había comprendido todo y que lo que más habían visto como difícil era trabajar en equipo. Estas fueron alguna de sus respuestas: “trabajar en grupo ha sido difícil porque no habíamos trabajado nunca", "fue complicado ponernos de acuerdo todos". Además, una de las respuestas más interesantes a esta pregunta fue la siguiente: “al principio no entendía los poemas de Góngora, pero con las canciones y las películas empecé a ver que era muy parecido todo". Con esta respuesta, se evidencia que la comprensión de poemas era un hándicap para alguno de los alumnos y que con la incorporación de canciones y películas actuales que tratan el mismo tópico literario pudieron establecer analogías que les facilitó la interpretación del poema.

Con la intención de comprobar si realmente esta estrategia había facilitado la comprensión de los poemas de Góngora, la tercera pregunta pedía a los alumnos que contestaran si creían que, gracias a la técnica de las constelaciones literarias, habían comprendido mejor los poemas de este autor. Todos los alumnos respondieron de manera unánime que sí. A continuación, citamos algunas de las respuestas más reiteradas:

Sí, porque es más fácil.

Sí, porque de otra manera es aburrido.

Sí, porque gracias a esta técnica hemos estado todos atentos.

Sí, ahora tengo una idea mucho más clara de lo que es la poesía de este autor.

Sí, lo hemos tenido mucho más cerca y lo hemos aprendido a distinguir.

Sí, las clases se me hacen más cortas y entiendo más las cosas.

La cuarta pregunta establecía si les gustaría que se utilizara más a menudo esta manera de enseñar la literatura. De nuevo, la respuesta de todos los alumnos fue afirmativa y la justificaron a través de las siguientes razones: "estamos atentos en clase", "se hace más fácil entender los poemas", "es más original”, "me lo he pasado muy bien y hacer cosas así veo que sirve para que otros compañeros en el pasillo lo vean”. 
La última de las preguntas del cuestionario era fundamental para la evaluación de la propuesta. En ella se pretende conocer qué era lo más importante que habían aprendido en las clases. Casi todas las respuestas atendían a que con ella habían conseguido comprender mejor los poemas, y no solo eso, a ser conscientes de que, pese a ser escritos siglos atrás, tratan temas actuales y, por tanto, de interés. A continuación, se recogen alguna de sus respuestas:

He aprendido que la poesía puede ser divertida y fácil de entender.

He aprendido que Góngora era un escritor que hablaba de temas que hoy siguen siendo importantes.

He aprendido que la poesía no es aburrida y puede ser fácil de entender.

He aprendido que la antigüedad y el ahora no se diferencian tanto.

He aprendido lo fácil que es entender un poema si lo relacionas con algo de nuestro día a día.

He aprendido que la literatura se puede leer de una forma más cercana.

En definitiva, con la revisión y evaluación de este instrumento, se constató que los alumnos experimentaron una propuesta didáctica diferente a las rutinarias, gracias a la cual consiguieron apreciar y disfrutar de la lectura del género poético y de un autor barroco como Góngora.

\section{Conclusiones}

El principal propósito de este proyecto ha sido la elaboración de una propuesta educativa que satisfaga por igual las necesidades y preferencias del alumnado al que se dirige y los requerimientos establecidos por el currículo. Con este fin, se ha presentado una propuesta innovadora, dinámica y didáctica en la que aspectos muy diversos de la educación literaria han culminado en la creación de cuatro constelaciones literarias a partir de la metodología "las constelaciones lectoras" desarrollada por Jover en Un mundo por leer (2007) y la estrategia didáctica de la gamificación (Marín, 2OI5).

Los resultados del proyecto han sido satisfactorios, puesto que, con él, se han cumplido los dos objetivos fundamentales que se perseguían. Por una parte, ha facilitado la comprensión del género poético a través de su relación con otros poemas, otros géneros literarios e incluso, con otras manifestaciones artísticas, consiguiendo así que el alumno establezca lazos de intertextualidad que le permitan entender su contenido y aumenten su interés literario. Por otra parte, ha ofrecido lecturas mediatizadas y adecuadas al contexto del aula a través de metodologías innovadoras como la gamificación y las constelaciones literarias, las cuales han aumentado la motivación del estudiantado y han favorecido el aprendizaje significativo de los alumnos. Todo esto se ha conseguido gracias a que se han aproximado los textos poéticos de Góngora a los alumnos para que perciban la pervivencia de sus poemas con respecto a la actualidad que les circunda. 
Con todo, se reconoce la necesidad de establecer vínculos entre el joven lector y las obras literarias (Lleida, 2Oı9; Romero Oliva, Ambós Pallerés y Trujillo Sáez, 2O2O); pues es a través de estas conexiones y redes intertextuales a partir de la cuales nace el acceso al significado, esto es, la comprensión e interpretación del texto (Ramos, 20I5: 85). Se trata, pues, de crear una relación interactiva entre el lector y el propio texto mediatizada por el docente, quien promueva que las diversas interpretaciones sean justificadas con cierta coherencia (Jover, 2008, 2009; Rovira, 20I9). De esta manera, la significatividad literaria a través de las constelaciones literarias será reforzada por la confrontación de textos literarios con correlatos artísticos contemporáneos con los que establecer comparaciones con su contemporaneidad. Con esta práctica, por tanto, se alcanza la construcción propia de significado durante y tras la lectura, desde una vertiente formativa y placentera, lo que constituye la meta última de la recepción lectora y, en definitiva, de la educación literaria (Mendoza, 2004: 46).

En suma, los resultados obtenidos del diseño y la puesta en práctica de esta propuesta de intervención educativa han evidenciado la necesidad de ofrecer distintos itinerarios lectores para aumentar el gusto por la lectura del género poético, en particular, y de una gran variedad de obras literarias, en general. En un futuro sería conveniente comprobar hasta qué punto, con esta práctica, los alumnos no solo son capaces de establecer relaciones con otros géneros y textos de otras épocas, sino también de qué modo y cómo ha repercutido todo ello en su capacidad para leer de forma autónoma los sonetos de Góngora.

En definitiva, en este trabajo, se ha acercado al alumnado a cada una de las caras de "esa creación poliédrica" que es la literatura (Moreno, 2003: 37). Todo ello, con el fin de dotar al alumnado de las herramientas necesarias para que en el futuro y de forma autónoma sepa, al leer una obra literaria, que son diversos y complementarios los puntos de vista que en ella se presentan y que lo fundamental es aprender a disfrutar de todos ellos. 


\section{Bibliografía}

-Álvarez, E.; Heredia, H. y Romero, M. F. (2OI9). La Generación Z y las redes sociales. una visión desde los adolescentes en España. Espacios, 4O(2O), 9-2I.

- Amar, V. (20I7). Ideas para un debate sobre tecnología y educación. Revista de Estudios Socieoeducativos, 5, I6-28.

- Ambrós, A. y Breu, R. (2OI4). Educar la mirada para la alfabetización múltiple. Hachetetepé, 8, 59-70.

- Ambrós, A. y Ramos, J. M. (2007). Veamos poesía: leamos imágenes en secundaria. Aula de Innovación Educativa, I65, 82-96. Obtenido el o2 de febrero de 202I desde http://blocs. xtec.cat/frac/files/2008/o4/a9_aulai65.pdf.

- Arenas Delgado, C.; Otero Doval, H. y Tatoj, C. (2O2O). Reading mediation in international contexts. The cases of Chile, Poland and Portugal. Investigaciones Sobre Lectura, I3, I69-I83.

- Argüelles, J. D. (20I6). Reflexiones y orientaciones sobre la educación poética. Textos de didáctica de la lengua y la literatura, 72, I6-2I.

- Ayuso Collantes, C. (2020). Por una lectura de los clásicos en la adolescencia. Álabe Revista de Investigación sobre Lectura y Escritura, 22, I-2I. DOI: http://dx.doi.org/IO.I5645/ Alabe2O2O.22.I

- Ballester J. e Ibarra, N. (2009). La enseñanza de la literatura y el pluralismo metodológico. Ocnos: revista de estudios sobre lectura, 5, 25-36.

- Ballester-Roca, J. y Ibarra-Rius, N. (20I6). La poesía en la educación lectora y literaria. Textos. Didáctica de la Lengua y de la Literatura, 72, 8-I5.

- Bibbó, M. (20i6). La voz de los lectores de poesía en la escuela secundaria. Textos de didáctica de la lengua y la literatura, 72, 40-43.

- Bombini, G. y Lomas, C. (20I6). La educación poética. Textos. Didáctica de la lengua y la literatura, 72, 4-7.

- Bordons, G. (2002). El reto de leer poesía. En G. Bordons; J. Ferrer; M. Naranjo y S. Rins (eds.). El reto de la lectura en el $S . X X I$ (pp. 243-252). Granada: Grupo Editorial Universitario.

- Bustamante Ramírez, E.; Alzaga Ruiz, I. y Observatorio de Cultura y Comunicación (coords.) (20I7). Informe sobre el estado de la cultura en España. Igualdad y diversidad en la era digital (ICE-2Or7). Madrid: Fundación Alternativas. Obtenido el $\mathrm{O} 2$ de febrero de 2O2I 
desde http:// www.fundacionalternativas.org/public/storage/publicaciones_archivos/6c d7ı7bd9f96codio2a67ı39fazeazac.pdf

- Calatayud, A. (2002). La cultura autoevaluativa, piedra filosofal de la calidad en educación. Educadores, 204, 357-375.

- Caldeiro, G. P. y Vizcarra, M. C. (2009). Trabajo cooperativo. Implicaciones pedagógicas del trabajo grupal. Obtenido el 02 de febrero de 2O2I desde https://educacion.idoneos. com/dinamica_de_grupos/trabajo_cooperativo/

- Caride, J. A.; Caballo, M. B. y Gradaílle, R. (20I8). Leer en tiempos de ocio: los estudiantes, futuros profesionales de la educación, como sujetos lectores. Ocnos: revista de estudios sobre lectura, I7 (3), 7-I8.

- Carreira, A. (1993). La décima de Góngora al Conde de Saldaña. Comentario de texto y reflexiones sobre la enseñanza de la literatura en el Bachillerato. RJLCE, 9, I7O-I93.

- Cassany, D. (20I6). Enseñar prácticas lectoras digitales. En S. Yubero; J. A. Caride; E. Larrañaga y H. Pose (coords.). Educación social y alfabetización lectora (pp. 77-98). Madrid: Síntesis

- Cerrillo, P. C. y Senís, J. (2005). Nuevos tiempos, ¿nuevos lectores? Ocnos: revista de estudios sobre lectura, I, I9-33.

- Clandinin, D. J., y Connelly, F. M. (2000). Narrative inquiry: Experience and story in qualitative research. San Francisco: Jossey-Bass Publishers.

- Cordón-García, J. A. (20I6). La investigación sobre el entorno digital. Métodos de Información, 7(13), 247-268.

- Federación de Gremios de Editores de España (2019). Hábitos de lectura y compra de libros en España 2018. Madrid - Ministerio de Cultura y Deporte: Conecta. Obtenido el o2 de febrero de 2O2I desde http://federacioneditores.org/lectura-y-compra-de-libros2or8.pdf.

- Fernández, S. y Llorens, R. (2005). La poesía en la Educación Secundaria Obligatoria. Primeras noticias. Revista de literatura, 213, 4I-44.

- Fraguela, R.; Pose, H. y Varela, L. (20I6). Tiempos escolares y lectura. Ocnos: revista de estudios sobre lectura, $5_{5}^{(2), 67-76 .}$

- Gallego, F.; Molina, R.; y Llorens, F. (20I4). Gamificar una propuesta docente. Diseñando experiencias positivas de aprendizaje. XX Jornadas sobre la Enseñanza Universitaria de la Informática, Oviedo: AENUI. Obtenido el o2 de febrero de 2O2I desde http://hdl.handle. net/IOO45/39195. 
- García Carcedo, P. (2018). Versos para amar. Poemas de educación emocional. República de Moldavia: Editorial Académica Española.

- García-Roca, A. (20r9). La lectura digital como actividad social y creativa: los fanfictions de Harry Potter. En J. M. de Amo Sánchez (Coord.). Nuevos modos de lectura en la era digital (pp. 75-96). Madrid: Síntesis.

- Garvis, S. (2015). Narrative Constellations. Exploring Lived Experience in Education. Gothenburg, Sweden: Sense publishers, University of Gothenburg.

- Gómez Martín, F. (2002). Didáctica de la poesía en la Educación Secundaria. Madrid: Instituto superior de formación del profesorado. Ministerio de Educación, Cultura y Deporte.

- Gómez, I. (2002). Los hábitos lectores. En J. A. Millán (coord.). La lectura en España. Informe 2002 (pp. 93-г9I). Madrid: Federación de Gremios de Editores de España.

• Góngora, L. (I991). Luis de Góngora para niños. Madrid: Ediciones de la Torre.

- Guiñez, M. y Martínez, E. (20I5). Mediación lectora y primera infancia: Construcción de sentidos subjetivos. Estudios Pedagógicos, 4I, II5-I34.

- Jover, G. (2007). Un mundo por leer. Educación, adolescentes y literatura. Barcelona: Octaedro.

- Jover, G. (2008). Se está haciendo cada vez más tarde (Por una literatura sin fronteras). En C. Lomas (coord.). Textos literarios y contextos escolares. La escuela en la literatura y la literatura en la escuela (pp.I49-I78). Barcelona: Graó.

- Jover, G. (coord.) (2009). Constelaciones literarias. Sentirse raro. Miradas sobre la adolescencia'. Málaga: Consejería de Educación de la Junta de Andalucía.

- Kress, G. R. (20IO). Multimodality: A Social Semiotic Approach to Contemporary Communication. London y New York: Routledge

- La Ley Orgánica 8/20I3, de 9 de diciembre, para la Mejora de la Calidad Educativa, modificó el artículo 6 de la Ley Orgánica 2/2006 (LOMCE), de 3 de mayo, de Educación. BOE $\mathrm{n}^{\circ} 3$. Obtenido el o2 de febrero de 2O2I desde http://www.educaragon.org/FILES/Lengua\%2oCastellana\%2oy\%2oLiteratura\%2Oі\%С2\%BA-4\%(2\%BA\%2oES\%282\%29.pdf

- Laguna, G. (I999). En tierra, en humo, en polvo, en sombra, en nada: historia de un tópico literario. Anuario de Estudios Filológicos, XXII, 197-2I3.

- Larragaña, M. E. y Yubero, S. 20I8. La influencia del hábito lector en el empleo de internet: un estudio con jóvenes universitarios. Bibliotecológica, 33(79), 51-66. 
- Lleida, E. (20I9). Itinerarios lectores para la educación poética en la ESO: del rap a la poesía canónica. Bellaterra Journal of Teaching \& Learning Language \& Literature, I2(4), 44-60.

- López Herrerías, J. A. (2003). Poesía y educación. Barcelona: Herder.

- Marín, V. (20I5). La Gamificación educativa. Una alternativa para la enseñanza creativa. Digital Education Review, 27, I-4.

- Martínez, E. y González, A. M. (2OIO). La comunicación digital: nuevas formas de lecturaescritura. Revista Quaderns Digitals, 63, I-I8.

- Martos Núñez, E. (2OI3). Lectura y patrimonio cultural en la era digital. Platero, I93, 3-24. Obtenido el I de abril de 202I desde https://issuu.com/cprovi/docs/platero_I93.

- Mckenna, M.; Conradi, K.; Lawrence, C.; Gee, B. y Meyer, P. (2OI2). Reading attitudes of middle school students: results of a U.S. survey. Reading Research Quarterly, 47(3), 283-306.

- Mendoza Fillola, A. (2008). El Intertexto lector. Sección de Literatura Infantil y Juvenil. Crítica e Investigación. Alicante: Biblioteca Virtual Miguel de Cervantes. Handbook of Research on Tejuelo, 29(2019), 275-312.

- Mendoza Fillola, A. (2012). Leer hipertextos. Del marco hipertextual a la formación del lector literario. Barcelona: Octaedro.

- Mendoza, A. (2004). La educación literaria: bases para la formación de la competencia lectora-literaria. Málaga: Aljibe.

- Micó, J. M. (2OI5). Para entender a Góngora. Barcelona: Acantilado.

- Millán, J. A. (200O). La lectura y la sociedad del conocimiento. Navarra: Gobierno de Navarra. Departamento de Educación. Obtenido el o2 de febrero de 202I desde http://dpto. educacion.navarra.es/publicaciones/pdf/lecturajamillan.pdf.

- Millán, J. A. (coord.) (2008). La lectura en España Informe 20o8. Leer para aprender. Madrid: Federación de Gremios de Editores de España.

- Molina Villaseñor, L. (2006). Lectura y educación: los hábitos lectores y su repercusión académica en Educación Secundaria Obligatoria, Ocnos: revista de estudios sobre literatura, 2, IO5-I22.

- Morales, M. (2005). Comparación de temas, topoi y motivos en la literatura española. Madrid: Liceus -E-xcelence.

- Morales, P. (2OII). El 'one minute paper'. Documento de trabajo de la Universidad Ponti- 
ficia Comillas. Obtenido el o2 de febrero de 202I desde http://www.upcomillas.es/personal/peter/otrosdocumentos/OneMinutePaper.pdf.

- Moreno, C.; Guzmán, F. y García, E. (2OI7). Los hábitos de lectura y escritura en los estudiantes de Educación Primaria: un análisis Dentro y Fuera de la escuela. Porta Linguarum, $2, \mathrm{II} 7$-I 37 .

- Munita, F. y Manresa, M. (2OI2). La mediación en la discusión literaria. En T. Colomer y M. Fittipaldi (eds.). La literatura que acoge: inmigración y lectura de álbumes (pp. II9-I43). Barcelona: Banco del Libro-Gretel-SM.

- Orden ECD/489/2Or6, de 26 de mayo, por la que se aprueba el currículo de la Educación Secundaria Obligatoria y se autoriza su aplicación en los centros docentes de la Comunidad Autónoma de Aragón.

- Orta, S. (2012). ¿Cómo se enseña la literatura del Siglo de Oro en Bachillerato? Almería: Prensas Universidad de Almería.

- Peña, M. (20IO). Entrevista con Roger Chartier. Las revoluciones del libro y la lectura: del códice al hipertexto. Álabe Revista de Investigación sobre Lectura y Escritura, I, I-7. DOI: http://dx.doi.org/ıo.I5645/Alabe.2OIO.ı.8

- Querol, J. M. (2OII). La función de las relaciones y dependencias textuales: materias, temas y motivos en la interpretación de textos literarios. Revista de Investigación e Innovación Educativa del Instituto Universitario de Ciencias de la Educación, 4I, 7I-87.

- Ramos, F. (2OI5). Barroco, hoy: propuesta didáctica de enseñanza literaria en el aula del siglo XXI. Revista de literaturas hispánicas, I, 8I-94.

- Real Decreto IIO5/20I4 [en línea]. Boletín Oficial del Estado, 3 de enero de 20I5. Obtenido el o2 de febrero de 2O2I desde https://www.boe.es/boe/dias/2OI5/oI/o3/pdfs/ BOE-A-2OI5-37.pdf).

- Rojas-Castro, P. (2OI7). Learning Analytics: una revisión de la literatura. Educación y Educadores, 2O(I), IO6-I28.

- Romero-Oliva, M. F.; Trigo-Ibáñez, E. y Moreno-Verdulla, P. (20I8) De la comprensión lectora a la competencia literaria a través de la obra de Eliacer Cansino. Ocnos: revista de estudios sobre literatura, I7(3), 68-85.

- Rovira-Collado, J. (20I9). Clásicos literarios en constelaciones multimodales. Análisis de propuestas de docentes en formación. Tejuelo, 29, 275-312.

- Rovira-Collado, J.; Serna Rodrigo, R. y Bernabé Gallardo, C. (2OI6). Nuevas estrategias 
digitales para la Educación Literaria: gamificación y narrativas transmedia en constelaciones literarias. En R. Roig-Vila (ed.). Tecnología, innovación e investigación en los procesos de enseñanza-aprendizaje (pp. 2968-2976). Barcelona: Octaedro.

- Sáez, J. L. y Rodríguez, M. P. (2003). Una nueva técnica docente. El punto más dudoso. Lugo: Asociación Española de Economía de la Empresa - XIII Jornadas Hispano- Lusas de Gestión Científica. Obtenido el o2 de febrero de 2O2I desde http://www.ti.usc.es/lugoxiiihispanolusas/pdf/o7_EXP_DOCENTES/o2_saez_rodriguez.pdf

- Serna, M.; Rodríguez, A. y Etxaniz, X. (2OI7). Biblioteca escolar y hábitos lectores en Educación Primaria. Ocnos: revista de estudios sobre literatura, I6(I), I8-49.

- Serna, R. (20I6). Videojuegos y Educación Literaria. Narrativas transmedia en las constelaciones literarias. Alicante: Departamento de Innovación y Formación didáctica. Especialidad en Didáctica de la Lengua y la Literatura.

- Tabernero Sala, R.; Álvarez Ramos, E.; y Heredia Ponce, H. (2O2O). Reading habits and information consumption of adolescents in the digital environment. Investigaciones Sobre Lectura, $13,7^{2-89}$.

- Trigo Ibáñez, E.; Santos Díaz, I. C. y Sánchez Rodríguez, S. (2020). What do Spanish adolescents read? A study of analog reading consumption. Investigaciones Sobre Lectura, i3, $35^{-} 53$.

- Unsworth, L. (20I4). Multimodal reading comprehension: curriculum expectations and large-scale literacy testing practices, Pedagogies: An International Journal, 9(I), 26-44.

- Wyatt-Smith, C. M y Elkins, J. (2008). Multimodal reading and comprehension in online environments. Handbook of Research on Tejuelo, 29(2019), 275-312.

- Zaldívar Sansuán, R. (20I4). El desarrollo de la conciencia emocional en la adolescencia a través de la poesía. Madrid: Universidad Autónoma de Madrid. Obtenido el o2 de febrero de 2O2I desde https://eprints.ucm.es/id/eprint/29989/I/El\%2odesarrollo\%2ode\%2ola\%2oconciencia\%2oemocional\%2oen\%2ola\%2oadolescencia\%2oa\%2o trav\%C $3 \%$ Ags\%2ode\%2ola\%2opoes\%C $3 \% A D a \_R a q u e l \% 20 Z a l d \% C_{3} \% A D v a r \% 20$ Sansu\%C3\%Ain.pdf.

- Zaldívar Sansuán, R. (2020). The emotional dimension in poetic education as a key to improve adolescents' attitudes towards poetry. Investigaciones Sobre Lectura, I4, 75-93.

- Zaldívar, R. (20I7). Las actitudes de los adolescentes hacia la poesía, su didáctica y la educación emocional en la ESO. Didáctica. Lengua y literatura, 29, 259-277.

- Zayas, F. (2OII). La educación literaria. Cuatro secuencias didácticas. Barcelona: Octaedro. 


\section{ANEXO I. LAS CUATRO GALAXIAS DE GÓNGORA: LAS CONSTELACIONES LI-} TERARIAS

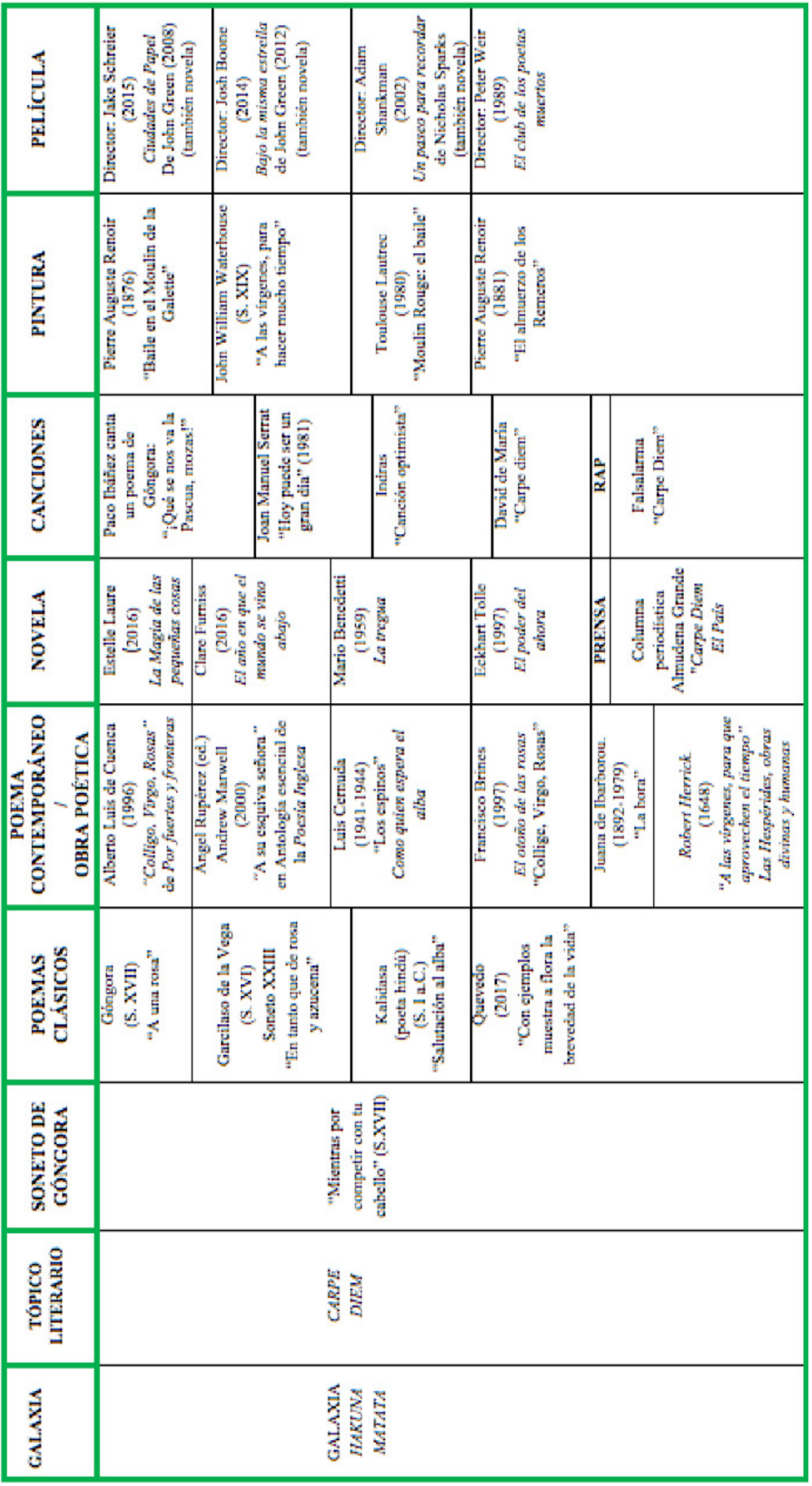




\begin{tabular}{|c|c|c|c|c|c|c|c|}
\hline 资 & 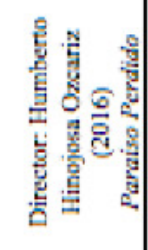 & 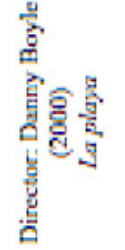 & 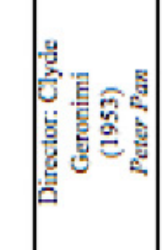 & & & & \\
\hline 点 & 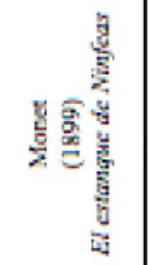 & 尊 & & & & & \\
\hline 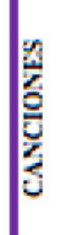 & 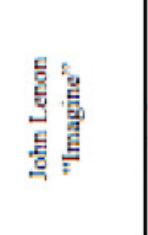 & 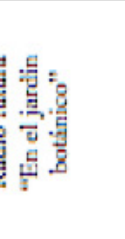 & 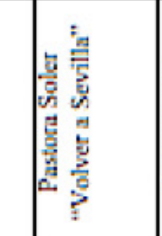 & 造 & 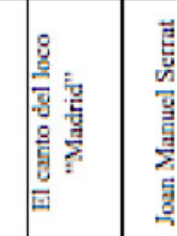 & ? & \\
\hline 趟 & 皇量 & 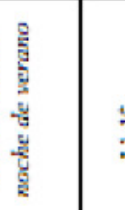 & 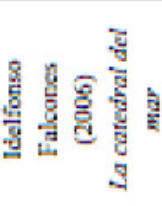 & & 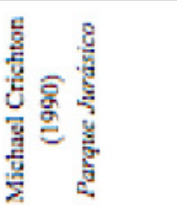 & & \\
\hline 产 & 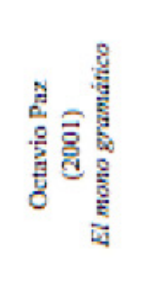 & 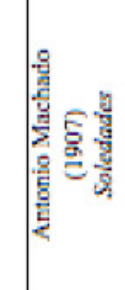 & 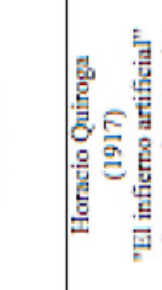 & 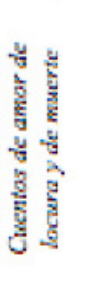 & 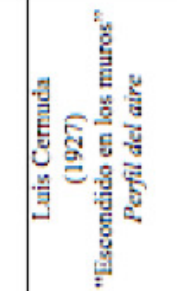 & 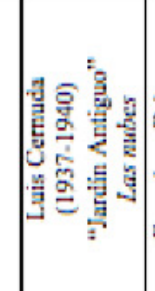 & 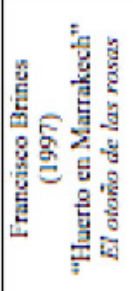 \\
\hline 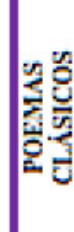 & 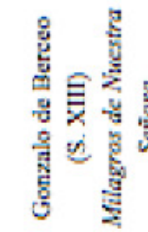 & & 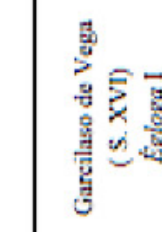 & हैं & 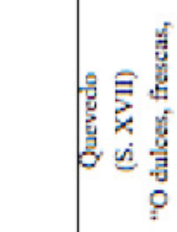 & 急 & \\
\hline 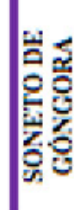 & & & & 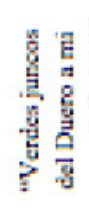 & & & \\
\hline 造 & & & & 8 & & & \\
\hline కృ & & & & 茪。 & & & \\
\hline
\end{tabular}




\begin{tabular}{|c|c|c|c|c|}
\hline$\stackrel{\substack{3\\
}}{3}$ & 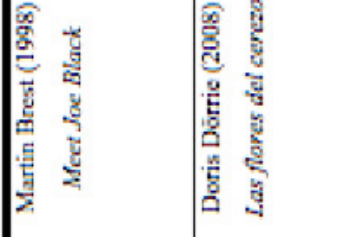 & 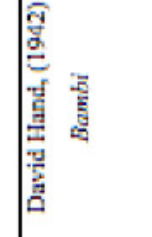 & & \\
\hline$\frac{n}{2}$ & 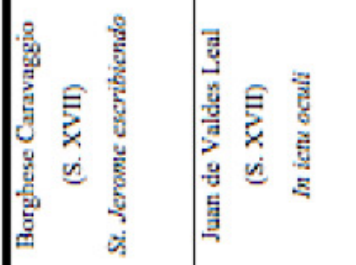 & 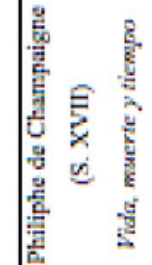 & & \\
\hline 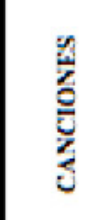 & 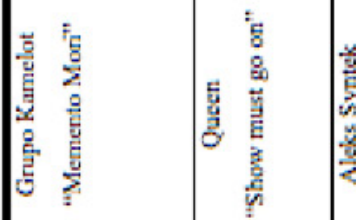 & 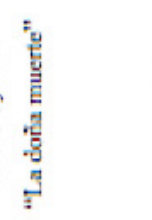 & 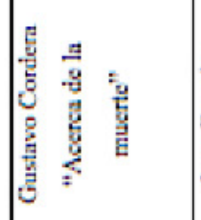 & 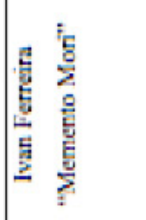 \\
\hline$\frac{3}{3}$ & 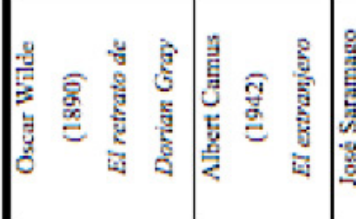 & 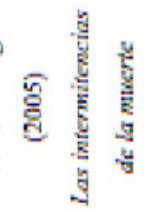 & 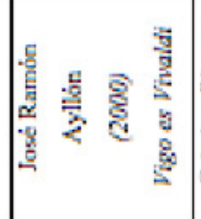 & 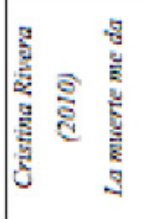 \\
\hline 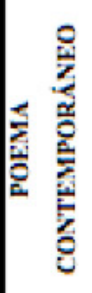 & 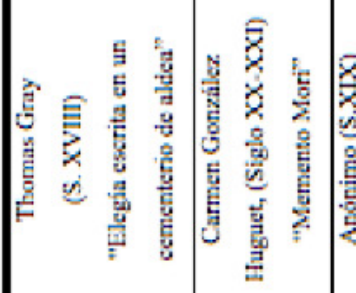 & & 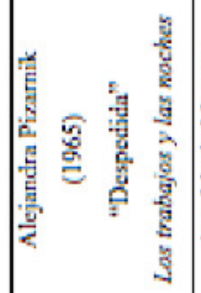 & $\begin{array}{ll} \\
0 \\
0\end{array}$ \\
\hline 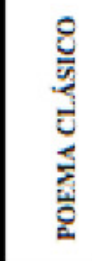 & 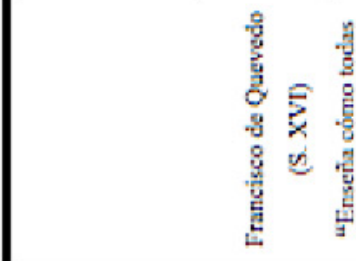 & 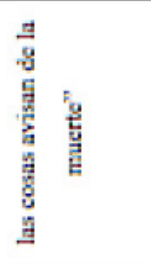 & & \\
\hline 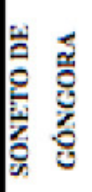 & $\stackrel{g}{g}$ & 势言 & & \\
\hline 象总 & & 要 & & \\
\hline ț. & & 氙 & & \\
\hline
\end{tabular}




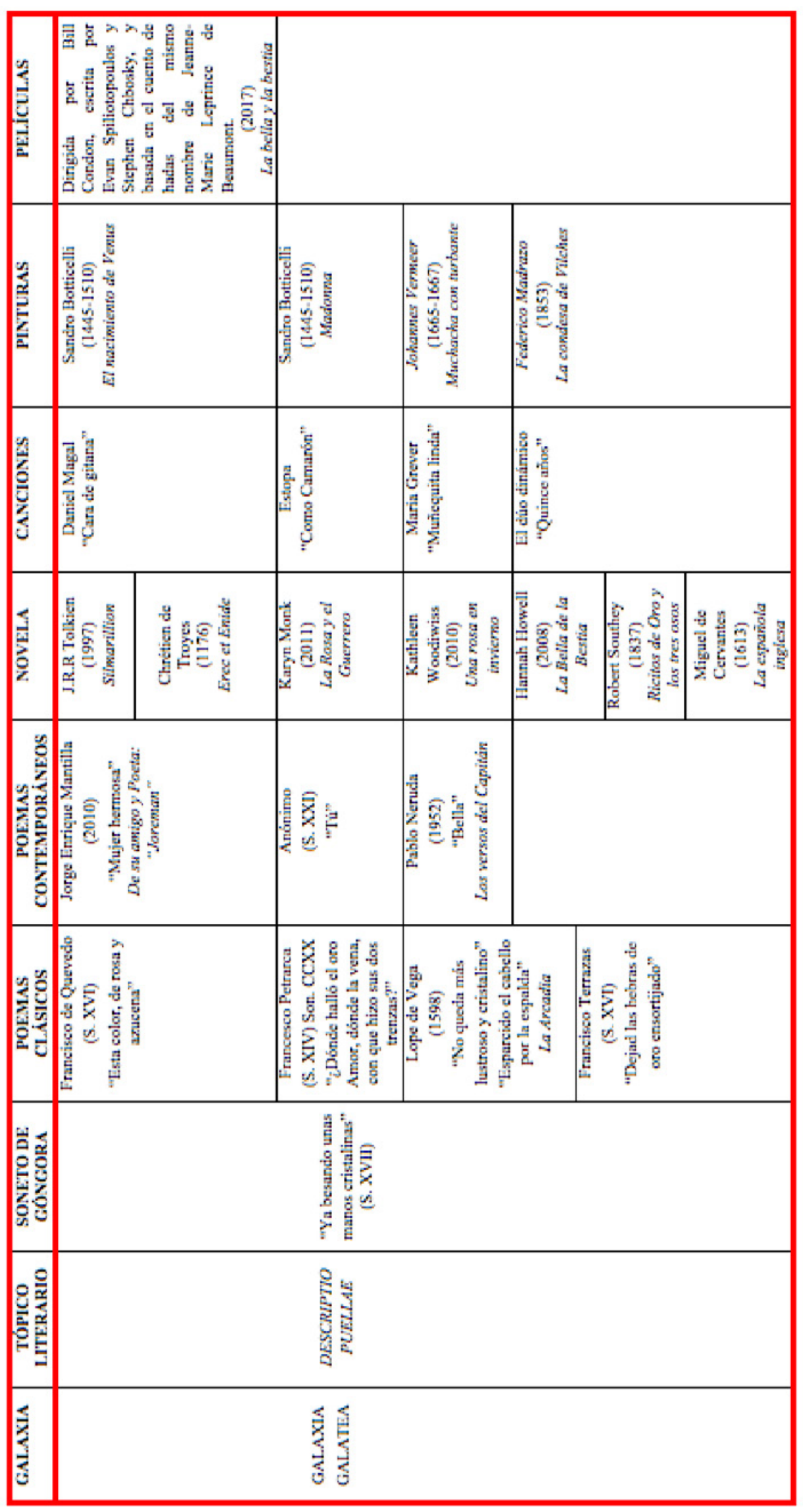




\section{ANEXO II: CUESTIONARIO ONEMINUTE PAPER}

\section{ONE MINUTE PAPER}

I. ¿Qué ha sido lo que más te ha gustado de estas sesiones de literatura? Justifica tu respuesta.

2. ¿Qué es lo que más difícil te ha parecido de entender?

3. ¿Crees que gracias a la técnica de las constelaciones literarias has comprendido mejor los poemas del barroco? Justifica tu respuesta.

4. ¿Te gustaría que se utilizara más a menudo esta manera de enseñar la literatura? Justifica tu respuesta.

5. ¿Qué ha sido para ti lo más importante que has aprendido en estas clases? Justifica tu respuesta 